\title{
A Study on Employee Welfare and Safety Measure Practiced in BESCOM Bangalore South
}

\author{
Bhaskar Shetty ${ }^{1}$, Shree Vidya V² \\ 1Professor, ${ }^{2}$ Student \\ 1,2SJR College for Women, Bengaluru, Karnataka, India
}

\begin{abstract}
How to cite this paper: Bhaskar Shetty | Shree Vidya V "A Study on Employee Welfare and Safety Measure Practiced in BESCOM Bangalore South" Published in International Journal of Trend in Scientific Research and Development (ijtsrd), ISSN: 24566470, Volume-3 | Issue-4, June 2019, pp.723-725, URL: https://www.ijtsrd.c om/papers/ijtsrd23 890.pdf

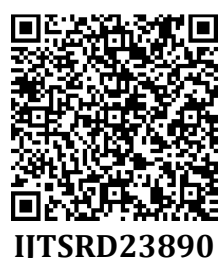

Copyright (C) 2019 by author(s) and International Journal of Trend in Scientific Research and Development Journal. This is an Open Access article distributed under the terms of the Creative Commons

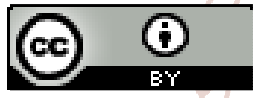
Attribution License (CC BY 4.0) (http://creativecommons.org/licenses/ by $/ 4.0$ )

\section{ABSTRACT}

This research work aims to study the welfare schemes practiced and safety measures provided for the employees. Safety and welfare are two areas that play a significant role in the achieving productivity and job satisfaction in any organization. As a result of accidents the organization loses a number of manhours and this loss affects a number of man-hours and this loss affects the productivity

Employee welfare and safety at the workplace is of the work place organization ensure that employees are exposed to a risk level which do not affect their physical emotional and mental health. Also the organization do not encourage any activity which will disturb the work life of the employees.Employees are trained appropriately about the work and about all precautionary measures that will prevent accidents at the work place.

Keywords: welfare measures, safety, man-hours, risk

\section{INTRODUCTION}

Human resource management (HRM) is the set of effective activities within an organization that concentrate on transforming human being into useful resources. The activities include searching at right candidate, identify their knowledge, skills and attitude towards a specific job, observing the performance of the employees, employee motivation, effective communication, administration and training for increasing productivity and efficiency.
HRM is a deliberate and widespread approach to managing people and the workplace culture and environment. Effective human resource managing people and the workplace culture and environment .Effective human resource management enables employees to contribute effectively and productively to the overall company direction and the accomplishment of the organization's goals and objectives.

Employee welfare and safety at the workplace is of the work place organization ensure that employees are exposed to a risk level which do not affect their physical emotional and mental health. Also the organization do not encourage any activity which will disturb the work life of the employees .Employees are trained appropriately about the work and about all precautionary measures that will prevent accidents at the work place.

Employees at the BESCOM like lineman are exposed to high risk due to working condition.They need more training and have to be aware of safety measures that prevent them from accidents .For example they should be aware of how to use gloves helpmates, perks, work boots, work pants, anti-cut gloves and also look towards the welfare of the employee working in the organization to protect themselves from fire and smoke. The present study is aimed at observing the satisfaction level of the employees with respect to the safety and welfare measures adopted by BESCOM organization .It not only consider the giving the awareness of the employees about safety measures at the workplace undertaken by the BESCOM organization to ensure that its employees work under safe condition but also the utilization of same by employees.

\section{REVIEW OF LITRATURE:}

Effective measure to improve their morale and self-worth by various labor welfare measures both the statutory and voluntary. Safety and welfare measures are inevitably to any organization where workers are involved

$>$ PETER HASLE AND HANS JORGEN LIMBORG (1995): The scientific literature regarding preventive occupational health and safety activities in small enterprises has been reviewed in order to identify effective preventive approaches and to develop a future research strategy

\section{$>$ SIMON CHAPPLE AND TRACY MEARS(1996):}

Most OECD countries rely on a mixture of market forces, tort liability, compulsory insurance and government regulation to deal with workplace safety and health issues. There are also other non-efficiency reasons for government involvement in workplace safety and health 
$>$ RABINSON,CLEGG(2000):

Is studied identified the key behavior which founded to be associated with employee welfare safety measures the behavior include belief in organization, desire to make thing better.

\section{JOHNSON B; RASK; STENBERG M (2010),}

This study was to carry out a broad and analysis of relevant research articles about piece rate wages and their effects on employee welfare and safety .A total of 47 research article were examined extensively and of those were found relevant and had sufficient quality to serve the purpose of this study.

\section{$>$ S SABARINATHAN;}

stated that this take a look at appropriately labor welfare degree in milk production co-operative union confined. The .The business enterprise suggest he high-quality deal of intangibility in assessment building and stocks in order throughout ranges.

\section{$>$ B RAJKUAR:}

stated that works are relatively unpreserved which needs regular welfare facilities for his or her up progression and presentation on this field In India service region and safety measures are important division which create additional service needs welfare procedures for their enhancement.

\section{$>$ N M JOSHI:}

stated that welfare activity comprises of all effort which employers take for the advantages of their employees over and above the wages paid or standard of working behavior allotted by the industry or by the company over and above provisions of the social legislation.

\section{SCOPE OF THE STUDY:}

The main scope of the study is to give the view about different activities conducted in organization. In this study only BESCOM organization in Bangalore south is covered and not any other organization. The organization and welfare safety measures adopted and how the company serves the employees, people, environment, society and nation. To study the extent of risk in the job exploring the security measures

\section{Employee welfare}

Employee welfare and safety at the workplace is of the work place organization ensure that employees are exposed to a risk level which do not affect their physical emotional and mental health .Also the organization do not encourage any activity which will disturb the work life of the employees .Employees are trained appropriately about the work and about all precautionary measures that will prevent accidents at the work place.

Employees at the BESCOM like lineman are exposed to high risk due to working condition .They need more training and have to be aware of safety measures that prevent them from accidents .For example they should be aware of how to use gloves helpmates, perks, work boots, work pants, anti-cut gloves and also look towards the welfare of the employee working in the organization to protect themselves from fire and smoke. The present study is aimed at observing the satisfaction level of the employees with respect to the safety and welfare measures adopted by BESCOM organization .It not only consider the giving the awareness of the employees about safety measures at the workplace undertaken by the
BESCOM organization to ensure that its employees work under safe condition but also the utilization of same by employees.

The study has been undertaken is one of BESCOM organization which has good system that ensures the safety of the employees. Therefore the study tried to disclose how employee is continuously motivated and focused to do duties with welfare measures given by the organization and safety measures adopted and practiced by the BESCOM organization.

Employee welfare include anything that is done for the comfort and improvement of the labor and is provided over and above wages .welfare helps in keeping the morale and motivation of the labor high so as to retain the labor for longer duration .The welfare measures need not be only a monetary it should be in any kind $\backslash$ form such that facilities, amenities which makes employees happy and satisfied it results in higher productivity of the organization.

\section{MEANING OF EMPLOYEE WELFARE}

Employee welfare refers to providing facilities, amenities and it is an action or activity done for development, intellectual and social of employee and these welfare facilities are paid, these facilities are given to employee to conduct their work in healthy and good

\section{OBJECTIVES OF THE EMPLOYEE WELFARE}

$>$ To provide better standard of life to the workers

$>$ To make employee satisfied and happy

To win over labor loyalty and increase their morale

$>$ To have constant labor force

$>$ To reduce labor turnover

To improve productivity of organization

$>$ To develop efficiency of worker

\section{FEATURES OF THE EMPLOYEE WELFARE}

$>$ Welfare incorporates different offices, administration and enhancements gave to specialist to improving their wellbeing, productivity financial advancement, proficiency.

D Welfare measures are in extra to customary wages and other monetary advantages accessible to laborers because of arrangement and aggregate dealing.

$>$ Work welfare conspire and adoptable and ever changes new welfare current ones every now and then

$>$ The Company gives better physical and psychological well-being to specialist and along these lines brief a solid situation.

$>$ Work gets steady work constrain by giving welfare office.

\section{MEANING OF SAFETY}

Safety in the organization means having workplace free from injury accidents and hazards

\section{Employee safety}

Employee safety refers to protection of workers from the danger of industrial accidents this is primarily a management activity which is concerned with reducing controlling and eliminating hazards from industrial units

\section{NEEDS FOR EMPLOYEE SAFETY}

Based on the employee risk quotient safety and safeguards, BESCOM employee can be divided into 3type:- 
$>$ Employee explore to low risk: Top level management and officer staff

$>$ Employee explore to moderate risk: Inspector, meter readers, testing staff like that.

$>$ Employee explore to high risk: Employee engaged in physical job of insulation maintenance and repair, lineman, field engineering

\section{SAMPLE DESIGN:}

\section{SAMPLING TECHNIQUE}

The sampling technique used is convenience sampling method.

\section{SAMPLING SIZE}

A sample size of 50 employees has been selected on the basis of convenience sampling method

\section{Discussion and conclusion}

$>$ It suggest that regular health checkup should be conducted once in six months

$>$ It suggest that BESCOM company should provide well advanced technical tools to the linemen when doing the field work

$>$ The company should make aware of the welfare schemes and other facilities available in the company to the employees.

$>$ It suggests to the company that the company maintain accidental books in a better way.

$>$ It suggests that company should organize recreational activities in the weekends.

$>$ The organization should provide special care or preference to the employees like linemen, temporary employees.

$>$ It suggests that provision of tools such that hand gloves, helmet respiratory mask, to ensure safety and minimizing accidents.

$>$ It suggests that to provide proper printing and stationery machines to increase the productivity or work.

$>$ It suggest that company should provide rest rooms for ladies and pregnant women's

$>$ The concept of employee welfare and safety measures is more relevant to working class compared to their western counter parties on account of the relatively poor working conditions and infrastructure

$>$ Well the fact that employees have always been the key for every organizational growth. There is a need to provide better working conditions and work environment.

$>$ proving the efficiency of employees since work related problems compliment poor quality of life for employees and decline in performance

$>$ proving the efficiency of employees since work related problems compliment poor quality of life for employees and decline in performance

$>$ proving the efficiency of employees since work related problems compliment poor quality of life for employees and decline in performance

$>$ When employees get better facilities like enough medical care, safe drinking facilities, welfare schemes, transportation such that those give employees a high level satisfaction. This provides opportunity to an organization to grow rapidly and sustainably.

$>$ Productivity and performance depends upon employee satisfaction.Hence there is a greater need to keep the employee happy and motivated welfare schemes and safety measures is on such tool for enhancing employee satisfaction

REFERENCE

\section{BOOKS REFFERED}

[1] DR. K NIRMALA."Human resource management “. Himalaya publications

[2] K.ASWATHAPPA, "Human resource management":

\section{WEBSITES}

[1] www.ijsrp.org

[2] www.hse.gov.uk

[3] 7 https://www.academia.edu

[4] https://www.researchgate.net

[5] https://www.slideshare.net

[6] https://educ.site

[7] Wc lee.hy wung.hh Lia 